\title{
Article
}

\section{Super-tough biodegradable poly(vinyl alcohol)/poly(vinyl pyrrolidone) blends plasticized by glycerol and sorbitol}

Boonsuk, Phetdaphat, Kaewtatip, Kaewta, Chantarak, Sirinya, Kelarakis, Antonios and Chaibundit, Chiraphon

Available at https://clok.uclan.ac.uk/21903/

Boonsuk, Phetdaphat, Kaewtatip, Kaewta, Chantarak, Sirinya, Kelarakis, Antonios orcid iconORCID: 0000-0002-8112-5176 and Chaibundit, Chiraphon (2018) Super-tough biodegradable poly(vinyl alcohol)/poly(vinyl pyrrolidone) blends plasticized by glycerol and sorbitol. Journal of Applied Polymer Science, 135 (26). p. 46406. ISSN 0021-8995

It is advisable to refer to the publisher's version if you intend to cite from the work. http://dx.doi.org/10.1002/app.46406

For more information about UCLan's research in this area go to

http://www.uclan.ac.uk/researchgroups/ and search for <name of research Group>.

For information about Research generally at UCLan please go to http://www.uclan.ac.uk/research/

All outputs in CLoK are protected by Intellectual Property Rights law, including Copyright law. Copyright, IPR and Moral Rights for the works on this site are retained by the individual authors and/or other copyright owners. Terms and conditions for use of this material are defined in the policies page. 
Super-tough biodegradable poly(vinyl alcohol)/poly(vinyl pyrrolidone) blends plasticized by glycerol and sorbitol

Phetdaphat Boonsuk, ${ }^{1}$ Kaewta Kaewtatip, ${ }^{1}$ Sirinya Chantarak, ${ }^{1}$ Antonios Kelarakis, ${ }^{2}$

Chiraphon Chaibundit ${ }^{1, *}$

${ }^{1}$ Department of Materials Science and Technology, Faculty of Science, Prince of Songkla University, Hat Yai, Songkhla, Thailand, 90110.

${ }^{2}$ Centre for Materials Science, School of Physical Sciences and Computing, University of Central Lancashire, Preston PR12HE, UK. 


\section{Abstract}

Tough biodegradable films were prepared using a poly(vinyl alcohol) (PVA)/poly(vinyl pyrrolidone) (PVP) (1:1) blend with plasticizers of glycerol, sorbitol and their (one to one) mixture. We studied the effect of plasticization on the structural, thermal and mechanical properties of the PVA/PVP blend films. FTIR spectra indicated good miscibility of the two components due to the H-bonding between the PVA and PVP molecules. The addition of plasticizers reduced the interaction between PVA and PVP, evidenced by an increase in the intensity of PVA diffraction peaks observed in the X-ray diffraction (XRD) characterization. Thermal degradation of the blends increased as a function of the plasticizer used. Glycerol affected thermal degradation more than sorbitol and the mixtures. The incorporation of the plasticizers promoted the growth of PVA crystals as evidenced by XRD patterns and the enthalpy of fusion $\left(\Delta H_{\mathrm{f}}\right)$ obtained by DSC measurements. The introduction of sorbitol to the binary blend increased toughness seven times and imparted simultaneous and pronounced improvements to maximum tensile stress and elongation at break. This behavior holds out great promise for the development of a new generation of mechanically robust, yet thoroughly biodegradable materials that could effectively supplant conventional polymers in demanding applications.

Keywords: poly(vinyl alcohol), poly(vinyl pyrrolidone), blend, plasticizer, tensile properties 


\section{Introduction}

It is well-known that a large percentage of the waste material in landfill is made up of plastics that will remain on sites for decades. Relief of landfill use and overall environmental impact is offered by biodegradable polymers, which are prone to physical decomposition via hydrolytic and enzymatic routes. ${ }^{1}$ Biodegradable polymers can be derived from natural products such as starch and cellulose ${ }^{2}$ or can be synthetic in nature, for example poly(lactides) and poly(glycolides). ${ }^{3}$ The major challenge that prevents their widespread use in a variety of applications stems from their relatively weak mechanical properties. Therefore, systematic efforts have been directed towards the improvement of these properties of biodegradable polymers. ${ }^{4-7}$

Poly(vinyl alcohol) (PVA) is a major artificial polymer that has been available for more than nine decades. ${ }^{8}$ Non-toxic, water-soluble and biodegradable, PVA is used industrially in textiles, paper coating, and food packaging,,${ }^{9,10}$ and also in the production of biodegradable film. ${ }^{11}$ It is a hydrophilic semi-crystalline polymer produced from the hydrolysis of poly(vinyl acetate) and contains hydroxyl groups which can be a source of hydrogen bonding. ${ }^{12,13}$

Poly(vinyl pyrrolidone) (PVP) is an amorphous, ${ }^{14}$ non-toxic and versatile polymer ${ }^{15}$ with a range of interesting properties. It is biodegradable and water soluble, has good environmental stability, is easily processed, moderately electrically conductive and has rich physics in charge transport mechanisms. ${ }^{16} \mathrm{PVP}$ is widely used as an excipient for pharmaceutical and personal care products, and is employed as a reducing agent and a surface stabilizer for nanoparticle synthesis, ${ }^{17}$ and as an insulating material in thin film transistors. ${ }^{18,19}$ When PVA and PVP are mixed, the interaction between PVA and PVP is 
expected to occur through inter-chain hydrogen bonding between hydroxyl groups of PVA and carbonyl groups of PVP. ${ }^{13,20}$

Developers of new materials often turn to polymer blends to obtain the properties they desire. ${ }^{21}$ PVA/PVP blends have been explored for wound dressing applications, ${ }^{22}$ local nitric oxide release, ${ }^{23}$ and insulation purposes. ${ }^{24}$ PVA/PVP (1:1) blends showed good charge storage capacity and good sensitivity for dopant additions. ${ }^{16,25,26}$ Several researchers studied the properties of PVA/PVP blends doped with azo dyes, ${ }^{27}$ inorganic salts,${ }^{28,29}$ and nanoparticles. ${ }^{25}$ A 4:1 blend of PVA/PVP doped with semiconducting silver sulfide particles produced a small band-gap composite. ${ }^{25}$

Plasticizers are low molecular weight, non-volatile compounds ${ }^{30}$ that impart flexibility to polymeric chains by weakening polymer-polymer intermolecular forces, and facilitating development of low density networks. ${ }^{7,31}$ They significantly influence the organization of the polymer chains, ${ }^{32}$ thus reducing the glass transition temperature $\left(T_{\mathrm{g}}\right)$ of polymers. ${ }^{33}$ In recent years, emphasis has been placed on the use of natural plasticizers such as glycerol ${ }^{4,34}$ and sorbitol ${ }^{7,35}$ that are non-toxic and resist migration.

We studied the effect of glycerol (GLY), sorbitol (SOR), and a glycerol-sorbitol mixture (GLY-SOR) on the physical and mechanical properties of low and high degree of hydrolysis PVA and PVA/PVP (1:1) blend films prepared by a solution casting method. The films were characterized by FTIR, XRD, TGA, and DSC techniques. The physical and the mechanical properties of the pure PVA, PVA/PVP films, and those containing plasticizers were compared. 


\section{Experimental}

\subsection{Materials}

Poly(vinyl alcohol) (PVA-1) (MW 90,000-110,000; 88 \% hydrolysis; viscosity 30.1 mPa s; The Nippon Synthetic Chemical Industry Co., LTD.), PVA-h (MW 89,000-90,000; 99 \% hydrolysis; Aldrich), poly(vinyl pyrrolidone) (PVP) (MW 40,000; Fluka), glycerol (Sigma-Aldrich) and sorbitol (Ajax) were used as received.

\subsection{Preparation of the films}

A series of PVA, PVP, PVA/PVP, and PVA/PVP/plasticizer films were prepared by a solution casting method using the various compositions listed in Table 1. As an example, one PVA/PVP/plasticizer blend was prepared by dissolving $5 \mathrm{~g}$ of PVA and $5 \mathrm{~g}$ of PVP in $100 \mathrm{~mL}$ of water under stirring at $95{ }^{\circ} \mathrm{C}$. After the dissolution of the polymers, plasticizer was added and the mixture was stirred for $30 \mathrm{~min}$. The solution was filtered through a kitchen sieve onto a polystyrene plate to get rid of bubbles and remove small amounts of undissolved low-hydrolysis PVA, and left overnight at room temperature. The solution was dried in an oven at $60{ }^{\circ} \mathrm{C}$ for $24 \mathrm{~h}$. An unplasticized PVP sample turned out to be brittle and broke into pieces after removal from the oven. Therefore, the stress-strain of this sample was not studied.

Table 1 Composition of the PVA/PVP blend films.

\begin{tabular}{llllll}
\hline Sample & PVA $(\mathrm{g})$ & PVP $(\mathrm{g})$ & glycerol $(\mathrm{g})$ & sorbitol $(\mathrm{g})$ & water $(\mathrm{mL})$ \\
\hline PVA & 10 & 0 & 0 & 0 & 100 \\
PVP & 0 & 10 & 0 & 0 & 100 \\
PVA/PVP & 5 & 5 & 0 & 0 & 100 \\
PVA/PVP/GLY & 5 & 5 & 3 & 0 & 100 \\
PVA/PVP/SOR & 5 & 5 & 0 & 3 & 100 \\
PVA/PVP/GLY-SOR & 5 & 5 & 1.5 & 1.5 & 100 \\
\hline
\end{tabular}




\subsection{Characterization of the films}

The FTIR spectra of the films were recorded on a Bruker Tensor 27 Fourier transform infrared spectrometer using the attenuated total reflectance in the frequency range of 600 to $4000 \mathrm{~cm}^{-1}$. The films were kept in a desiccator prior to testing. For each spectrum, 64 consecutive scans were recorded with a resolution of $4 \mathrm{~cm}^{-1}$.

X-ray diffraction (XRD) studies of the samples were carried out using a Phillips diffractometer (Model X'Pert MDI) with a scanning rate of $3 \%$ min with $\mathrm{CuK} \alpha$ radiation $(\lambda=$ $1.5410 \AA$ ) operating at $40 \mathrm{kV}$ and $30 \mathrm{~mA}$. The scanning range of $2 \theta$ was from 5 to $90^{\circ}$.

The thermal decomposition temperature of the films was determined using a Perkin Elmer STA8000. The thermogravimetric analysis (TGA) was performed at a heating rate of $10{ }^{\circ} \mathrm{C} \mathrm{min}^{-1}$ from 30 to $600{ }^{\circ} \mathrm{C}$ under a nitrogen atmosphere.

Thermal properties of the films were characterized by differential scanning calorimetry (DSC) using NETZSCH apparatus (DSC 200F3). The films were kept in a desiccator prior to testing. The sample, in an aluminum pan, was initially cooled to $0{ }^{\circ} \mathrm{C}$ and then heated to $250{ }^{\circ} \mathrm{C}$. Then, the sample was cooled from 250 to $0{ }^{\circ} \mathrm{C}$ and heated again from 0 to $250{ }^{\circ} \mathrm{C}$ at a cooling and heating rate of $10^{\circ} \mathrm{C} \mathrm{min}^{-1}$

\subsection{Mechanical testing}

The specimens were cut according to ASTM D638-03, Type V (width $=3.18 \mathrm{~mm}$, distance between grip $=25 \mathrm{~mm}$ ). Determination of the mechanical properties of the films was carried out with a Universal Testing Machine (Instron 3365) equipped with a $100 \mathrm{~N}$ load cell and operated at a cross-head speed of $20 \mathrm{~mm} / \mathrm{min}$. The samples were equilibrated for 7 days at room temperature and $75 \% \mathrm{RH}$ before testing. The measurements were taken at $25{ }^{\circ} \mathrm{C}$ and twelve specimens were determined per formulation. 


\section{Results and discussion}

\subsection{Structural of the films}

The FTIR spectra of PVP, PVA, pure PVA/PVP, PVA/PVP/GLY, PVA/PVP/SOR, and PVA/PVP/GLY-SOR are shown in Figure 1. The peak assignments of the films are listed in Tables $\mathbf{S} 1$ and $\mathbf{S} 2$ in the Supporting Information.
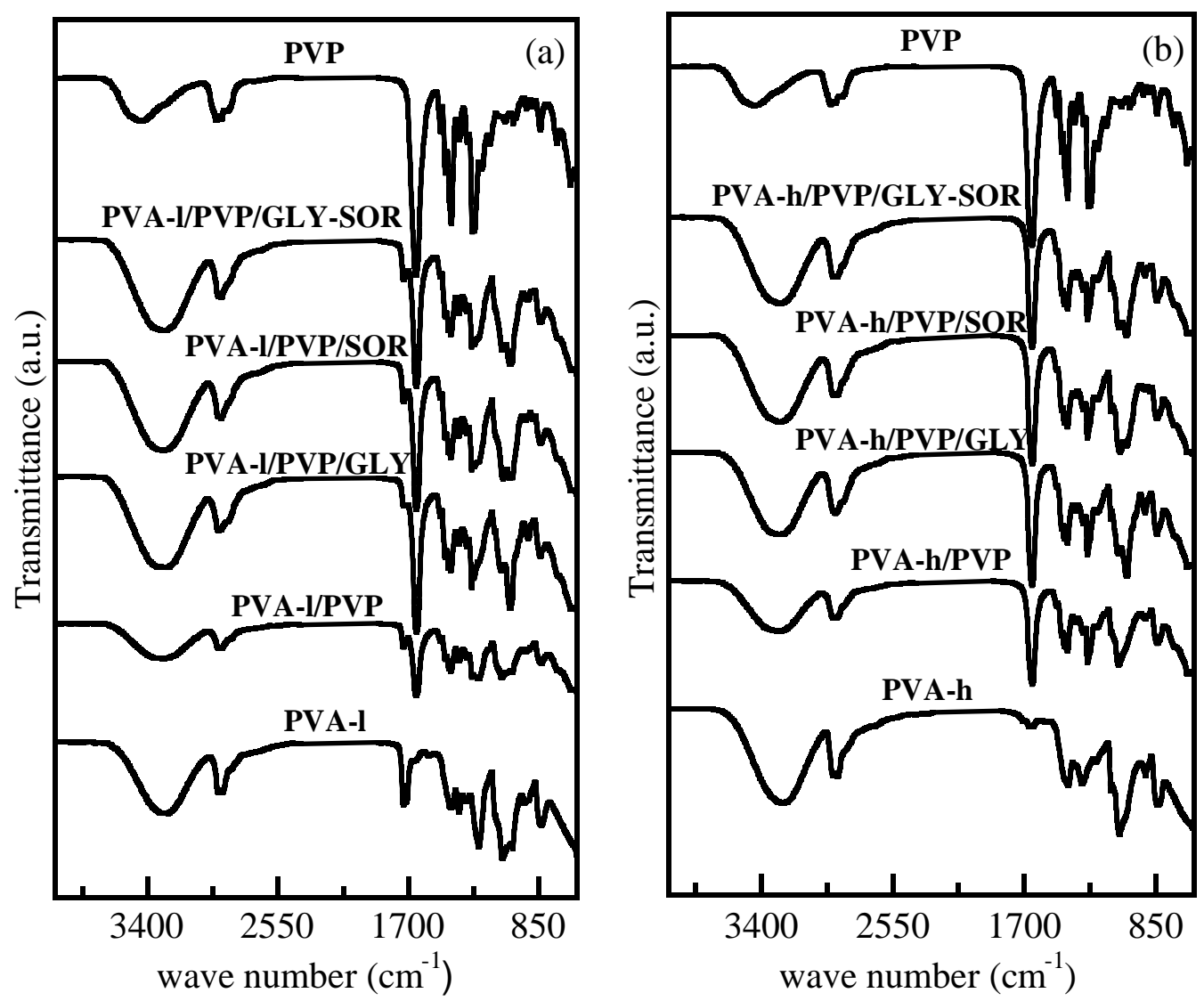

Figure 1. FTIR spectra for (a) PVA-1, pure PVA-1/PVP, PVA-1/PVP/plasticizer, and PVP and (b) PVA-h, pure PVA-h/PVP, PVA-h/PVP/plasticizer, and PVP films as indicated.

For PVP, the peaks located at 3446, 2950/2920, 1651 and 1284, and $1017 \mathrm{~cm}^{-1}$, are attributed to the stretching vibration of $-\mathrm{OH},{ }^{15,17,36}$ the $\mathrm{CH}_{2}$ stretching vibration, ${ }^{17}$ the $\mathrm{C}=\mathrm{O}$ vibration, ${ }^{36,37}$ and the $\mathrm{C}-\mathrm{N}$ vibration, ${ }^{17,38}$ respectively. 
Regarding PVA-1, the peaks at 3283, 2939/2911, and $1732 \mathrm{~cm}^{-1}$ are attributed to the stretching vibration of $-\mathrm{OH},{ }^{4,39,40}$ the $\mathrm{CH}_{2}$ asymmetric and symmetric stretching, ${ }^{39}$ and the $\mathrm{C}=\mathrm{O}$ stretching, ${ }^{40}$ respectively.

The pure PVA-1/PVP blend film showed peaks located at 3304, 2938/2917, 1733 and $1289 \mathrm{~cm}^{-1}$. Interestingly, in this system, the stretching vibration of $-\mathrm{OH}$ shifted to $3304 \mathrm{~cm}^{-1}$ due to the formation of hydrogen bonding between carbonyl groups of PVP and hydroxyl groups of PVA-1, indicating the improved miscibility of the two components at the molecular level. ${ }^{15}$ The addition of plasticizers to the blends partially reversed the shifting probably due to weakening of the hydrogen bonding between the PVA and PVP. The $-\mathrm{OH}$ peak, in cases of PVA-h/PVP based blends, had the same wave number around $3291 \mathrm{~cm}^{-1}$, except in the case of the PVA-h/PVP/GLY-SOR film.

\subsection{X-ray diffraction analysis}

The X-ray diffraction patterns of PVA-1, pure PVA-1/PVP, PVA-1/PVP/plasticizer films and PVP, and PVA-h, pure PVA-PVP, PVA-h/PVP/plasticizer films, and PVP are shown in Figures 2a and b, respectively. The diffraction peaks of PVA-l and PVA-h are located at $2 \theta \approx 19.3^{\circ}$ corresponding to orthorhombic (110) reflection ${ }^{28}$ and $40.6^{\circ}$, and are ascribed to the semi-crystalline nature of pure PVA. ${ }^{4,25,40}$ PVA-h exhibited a clearly defined peak at $2 \theta \approx 40.6^{\circ}$. The crystallinity of PVA arises from the strong intermolecular and intramolecular hydrogen bonding between polymer chains. ${ }^{41,42}$ The broad peaks in the diffraction pattern of PVP suggest that there is no diffraction and no long-range threedimensional molecular order. ${ }^{43}$ The absence of these characteristics is indicative of an amorphous compound..$^{13,43,44}$ 

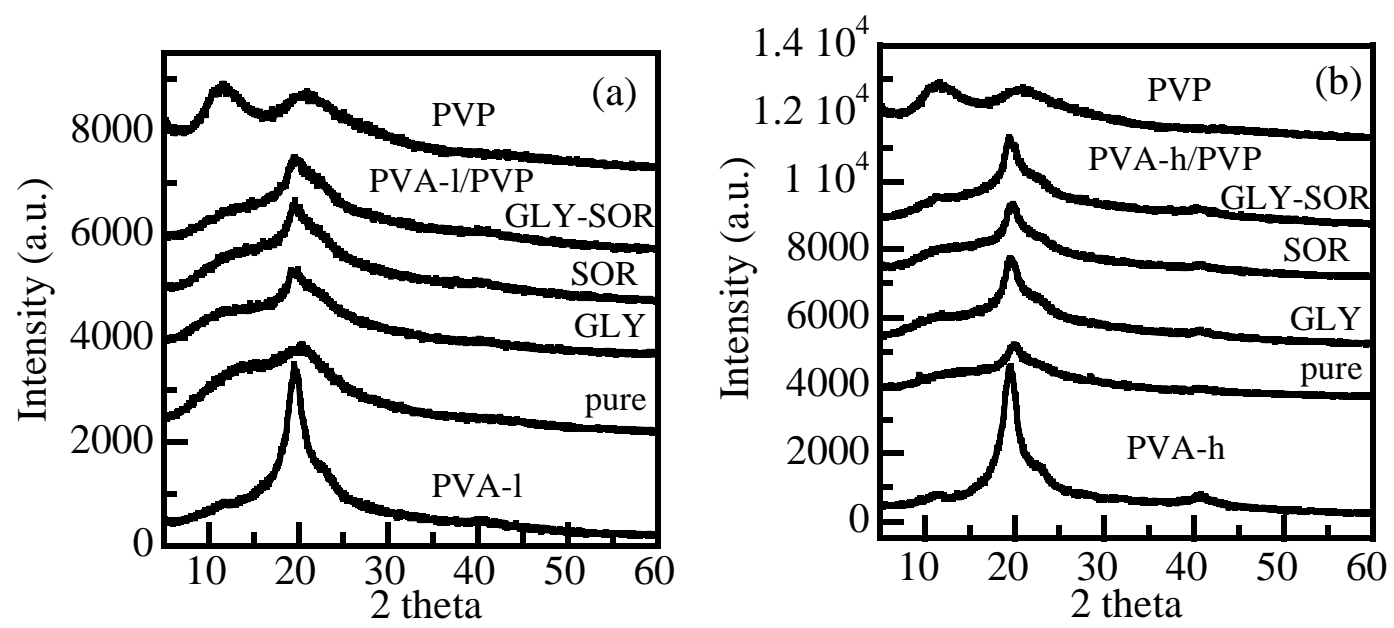

Figure 2. XRD patterns of (a) PVA-1 film, pure PVA-1/PVP film, PVA-1/PVP/plasticizer films, and PVP and (b) PVA-h film, pure PVA-h/PVP film, PVP-h/PVP/plasticizer film, and PVP as indicated.

The incorporation of PVP in PVA for pure PVA-1/PVP and PVA-h/PVP produced a diffraction peak at about $2 \theta \approx 20.1^{\circ}$ with lower sharpness and intensity compared to those of PVA-1 and PVA-h. The peaks exhibited by pure PVA at $2 \theta \approx 19.3$ and $40.6^{\circ}$ nearly vanished for PVA/PVP blends due to the high amorphous fraction in the PVA and PVP blends. ${ }^{25}$

The XRD patterns of PVA/PVP with added plasticizers exhibited shifted peaks at $2 \theta$ $\approx 19.3^{\circ},{ }^{45}$ a reduced peak intensity at $2 \theta \approx 40.6^{\circ}$, and a significant increase in the intensity of the diffraction peak at $2 \theta \approx 19.3^{\circ}$. The increased intensity indicated the plasticizing effect due to the insertion of plasticizer molecules among the polymer chains, which reduced the interaction between PVA and PVP chains. 


\subsection{Thermal behavior}

\subsubsection{Thermogravimetric analysis}

The TGA and DTG curves of PVP, PVA-1, pure PVA-1/PVP, PVA-1/PVP/plasticizer, PVA-h, pure PVA-h/PVP, and PVA-h/PVP/plasticizer films are shown in Figures 3a-b and $3 \mathrm{c}-\mathrm{d}$, respectively. The mass loss at $200{ }^{\circ} \mathrm{C}$ and residual weight are listed in Table 2 .
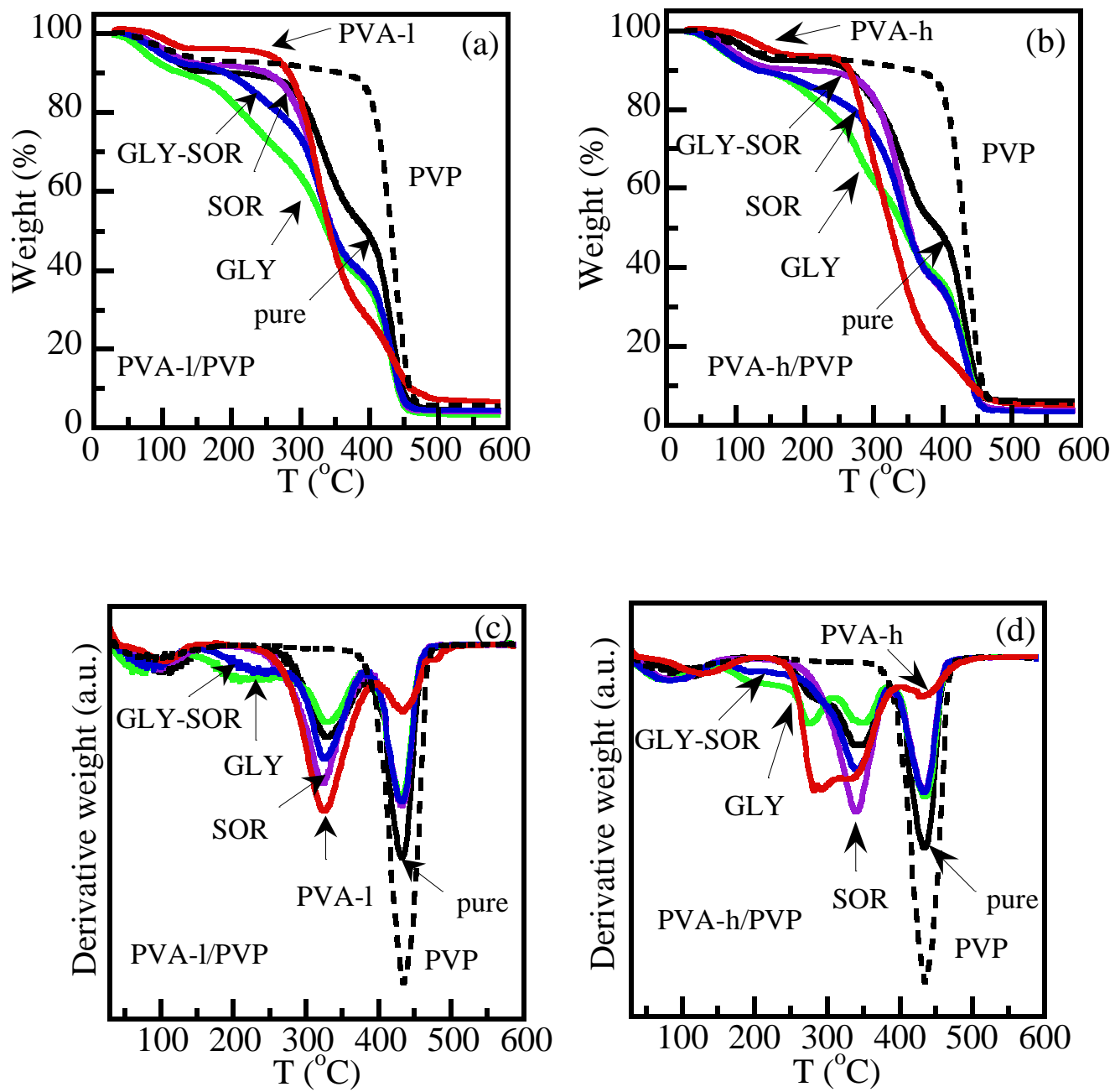

Figure 3. TGA thermograms of (a) PVP, PVA-1, pure PVA-1/PVP, and PVA1/PVP/plasticizer and (b) PVP, PVA-h, pure PVA-h/PVP, and PVA-h/PVP/plasticizer films and their DTG thermograms in (c) and (d) as indicated. 
Table 2 Results of TGA studies of PVP, PVA-1, pure PVA-1/PVP, PVA-1/PVP/plasticizer, PVA-h, pure PVP-h/PVP, and PVA-h/PVP/plasticizer films.

\begin{tabular}{lcc}
\hline Sample & Mass loss at $200{ }^{\circ} \mathrm{C}(\%)$ & Residual (\%) \\
\hline PVP & 7.01 & 5.61 \\
PVA-1 & 3.98 & 6.70 \\
PVA-h & 6.31 & 5.24 \\
\hline PVA-1/PVP & 9.93 & 4.58 \\
PVA-1/PVP/GLY & 17.28 & 3.28 \\
PVA-1/PVP/SOR & 8.21 & 3.98 \\
PVA-1/PVP/GLY-SOR & 10.68 & 4.39 \\
\hline PVA-h/PVP & 7.66 & 6.10 \\
PVA-h/PVP/GLY & 15.37 & 3.68 \\
PVA-h/PVP/SOR & 9.87 & 3.08 \\
PVA-h/PVP/GLY-SOR & 13.45 & 3.29 \\
\hline
\end{tabular}

In the pure PVA-1/PVP blend, the mass loss occurred in three stages: at $\mathrm{T} \approx 100{ }^{\circ} \mathrm{C}$, arising from loss of water; at $\mathrm{T} \approx 325^{\circ} \mathrm{C}$, arising from the elimination of water from PVA; and at $\mathrm{T} \approx 435^{\circ} \mathrm{C}$, arising from the pyrolysis of the residue into a carbonaceous product. ${ }^{46}$

In the PVA-1/PVP blends, the mass loss occurred at four stages depending on the plasticizer added: the loss of water at $\mathrm{T} \approx 100^{\circ} \mathrm{C}$, the degradation of glycerol at $\mathrm{T} \approx 210{ }^{\circ} \mathrm{C},{ }^{47}$ the degradation of sorbitol at $\mathrm{T} \approx 323{ }^{\circ} \mathrm{C},{ }^{48}$ and the thermal degradation of the polymers at $\mathrm{T}$ $\approx 327^{\circ} \mathrm{C}$ and $433^{\circ} \mathrm{C}$. Pure PVA-h/PVP films showed similar mass losses to pure PVA-1/PVP films. 
The plasticizers caused an increase of mass loss at $200{ }^{\circ} \mathrm{C}$, especially considerable when glycerol was added. This effect indicated that glycerol-plasticized PVA/PVP films have higher moisture contents than sorbitol-plasticized PVA/PVP films. ${ }^{49}$ The blends plasticized with sorbitol had higher resistance than those plasticized with glycerol and glycerol-sorbitol. The greatest effect on residual mass occurred with the addition of glycerol to PVA-1/PVP and sorbitol to PVA-h/PVP blend films, which respectively reduced the residual mass from 4.58 to $3.28 \%$ and from 6.10 to $3.08 \%$.

\subsubsection{Differential thermal analysis}

The DSC thermograms of PVP, PVA-1, pure PVA-1/PVP, PVA-1/PVP/plasticizer, and PVA-h, pure PVA-h/PVP, PVA-h/PVP/plasticizer films are shown in Figures $4 \mathrm{a}$ and b, respectively. Table 3 summarizes the data for all systems of $T_{\mathrm{g}}, T_{\mathrm{m}}$, calculated enthalpy of fusion $\left(\Delta H_{\mathrm{f}}\right)$, and degree of crystallinity $\left(X_{\mathrm{c}}\right)$, which was calculated using the following equation ${ }^{4}$ :

$$
X_{c}=\Delta H_{f} /\left(\Delta H_{f}^{0} W\right) \times 100
$$

where $\Delta H_{\mathrm{f}}$ is the apparent enthalpy of fusion of PVA/PVP blend, $W$ is the weight fraction of PVA in the blend, and $\Delta H_{f}^{0}$ is the enthalpy of fusion of $100 \%$ crystalline PVA (141.932 $\mathrm{J} / \mathrm{g}){ }^{50}$

As expected, PVP displayed a $T_{\mathrm{g}}$ close to $159.5{ }^{\circ} \mathrm{C}^{14}$ which was high because of the presence of the rigid pyrrolidone groups. ${ }^{26} \mathrm{PVA}-1$ film exhibited $T_{\mathrm{g}}$ and $T_{\mathrm{m}}$ at $74.7^{\circ} \mathrm{C}$ and 174.9 ${ }^{\circ} \mathrm{C}$ and PVA-h exhibited $T_{\mathrm{g}}$ at $78.6{ }^{\circ} \mathrm{C}$ and $T_{\mathrm{m}}$ at $229.4^{\circ} \mathrm{C}$. 

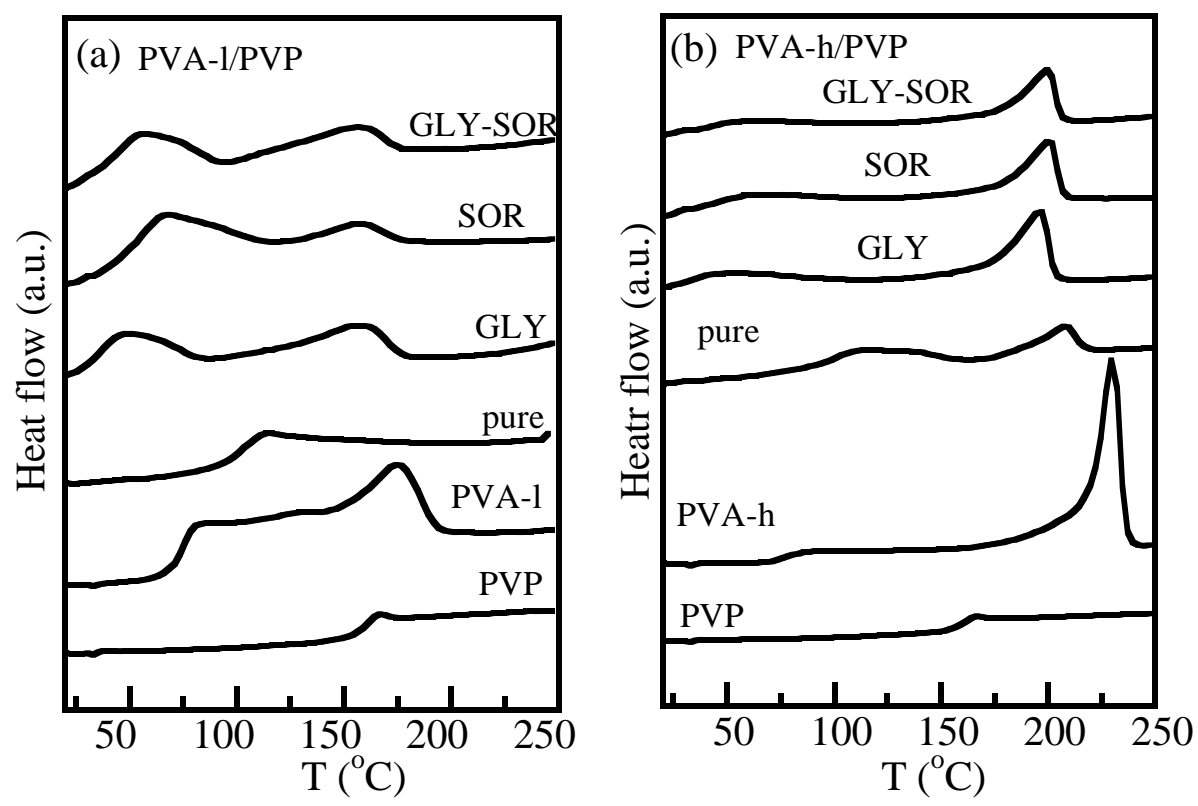

Figure 4 DSC thermograms of (a) PVP, PVA-1, pure PVA-1/PVP, and PVA-1/PVP/plasticizer and (b) PVP, PVA-h, pure PVA-h/PVP, and PVA-h/PVP/plasticizer films as indicated.

The DSC thermogram of pure PVA-1/PVP shows a single $T_{\mathrm{g}}$ at $104.6^{\circ} \mathrm{C}$, indicating the good miscibility of the polymer blends, ${ }^{51}$ which was attributed to the interaction between the hydroxyl groups of PVA and the carbonyl groups of PVP. ${ }^{52}$ Interestingly, $T_{\mathrm{m}}$ and $\Delta H_{\mathrm{f}}$ were absent from the PVA-1/PVP blend, whereas the addition of PVP to PVA-h produced $T_{\mathrm{m}}$ and $\Delta H_{\mathrm{f}}$ with reduced values. Pure PVA-h/PVP also shows a single $T_{\mathrm{g}}$ at $104.9^{\circ} \mathrm{C}$, consistent with the miscibility of the polymeric components ${ }^{53,54}$ and $T_{\mathrm{m}}$ at $208.3^{\circ} \mathrm{C}$, much lower than pure PVA-h. It has been reported by Lewandowska that the miscibility of PVP in the lower degree of hydrolysis of PVA ( $88 \%$ ) was better than the miscibility in the higher degree $(99 \%$ hydrolysis). ${ }^{52}$ Therefore, the miscibility of PVA-1/PVP was better than that of PVA-h/PVP due to the disappearance of the crystallinity of PVA-1 after the incorporation of PVP. The miscibility of pure PVA-1/PVP and pure PVA-h/PVP were also studied using SEM and the images are shown in Figure S1 in the Supporting Information. The fracture surfaces of PVA- 
1/PVP and PVA-h PVP blend films showed no phase separation, indicating the good miscibility of the two polymers ${ }^{55}$ due to the hydrogen bonding between PVA and PVP chains. ${ }^{13,20}$

Table 3. Glass transition $\left(T_{\mathrm{g}}\right)$, melting temperature $\left(T_{\mathrm{m}}\right)$, enthalpy of fusion $\left(\Delta H_{\mathrm{f}}\right)$ and degree of crystallinity $\left(X_{\mathrm{c}}\right)$ of PVP, PVA-1, pure PVA-1/PVP, PVA-1/PVP/plasticizer, PVA-h, pure PVP-h/PVP, and PVA-h/PVP/plasticizer films obtained from DSC.

\begin{tabular}{lcccc}
\hline Sample & \multicolumn{3}{c}{$2^{\text {nd }}$ heating scan } & $X_{\mathrm{c}}(\%)$ \\
\cline { 2 - 4 } & $T_{\mathrm{g}}\left({ }^{\circ} \mathrm{C}\right)$ & $T_{\mathrm{m}}\left({ }^{\circ} \mathrm{C}\right)$ & $\Delta H_{\mathrm{f}}\left(\mathrm{J} \mathrm{g}^{-1}\right)$ & \\
\hline PVP & 159.5 & - & - & - \\
\hline PVA-1 & 74.7 & 174.9 & 20.34 & 14.33 \\
PVA-1/PVP & 104.6 & - & - & - \\
PVA-1/PVP/GLY & 36.1 & 156.2 & 9.22 & 13.00 \\
PVA-1/PVP/SOR & 53.2 & 157.3 & 4.97 & 7.00 \\
PVA-1/PVP/GLY-SOR & 44.6 & 156.2 & 5.15 & 7.25 \\
\hline PVA-h & 78.6 & 229.4 & 58.78 & 41.41 \\
PVA-h/PVP & 104.9 & 208.3 & 8.43 & 11.88 \\
PVA-h/PVP/GLY & 37.3 & 196.3 & 23.08 & 32.53 \\
PVA-h/PVP/SOR & 44.6 & 200.3 & 18.55 & 26.13 \\
PVA-h/PVP/GLY-SOR & 42.8 & 199.7 & 16.05 & 22.62 \\
\hline
\end{tabular}

The addition of plasticizers had a significant effect on the values of $T_{\mathrm{g}}, T_{\mathrm{m}}$, and $\Delta H_{\mathrm{f}}$ of the blends. The interspersion of plasticizer molecules between the polymer chains of PVA-1 and PVP induced the crystallinity of the PVA-1 phase that PVP had suppressed, and reduced 
the miscibility between PVA-1 and PVP, lowering the $T_{\mathrm{g}}$ temperatures and causing $T_{\mathrm{m}}$ to reappear. In the case of the PVA-h/PVP blends, the addition of the plasticizers reduced the values of $T_{\mathrm{g}}$ and $T_{\mathrm{m}}$, but increased $\Delta H_{\mathrm{f}}$, and the PVA-h blends overall showed higher values of $T_{\mathrm{m}}$ and $\Delta H_{\mathrm{f}}$ than the PVA-1 blends. The addition of plasticizers in the PVA-h blends decreased $T_{\mathrm{m}}$ and $\Delta H_{\mathrm{f}}$ because the plasticizers induced the crystallinity of the PVA.

Blending PVP with PVA-h reduced $X_{c}$ to $12 \%$ compared to $41 \%$ recorded for the pure PVA-h. However, this effect was partially reversed when the blends were plasticized with glycerol, sorbitol and their mixtures, which produced $X_{c}$ close to 33, 26 and 23\%, respectively. In general lines, those observations are consistent with the XRD data (Figure 2) that indicate a sharp, but weak diffraction peak at $2 \theta \approx 19.3^{\circ}$ for the PVA-h/PVP blend (the amorphous halo at lower 2 theta corresponds to PVP). ${ }^{45}$ However, the addition of the plasticizers to the PVA-h/PVP blend significantly increased the intensity of the diffraction peak, in response to the higher degree of crystallinity. Similar trends can be seen on the XRD spectra of the PVA-1/PVP based blends.

\subsection{Mechanical properties}

Figures 5a and $\mathrm{b}$ compare the stress-strain curves obtained for PVA-1, pure PVA1/PVP, and its blends with plasticizers and PVA-h and PVA-h/PVP systems, respectively. 

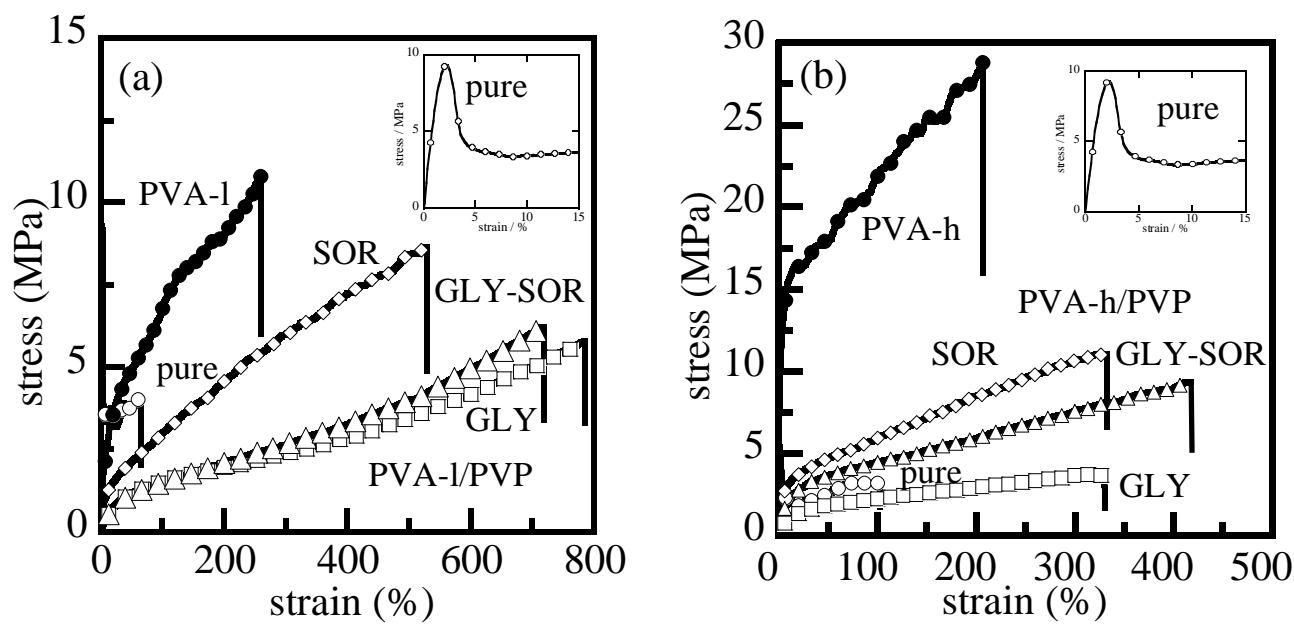

Figure 5. Stress-stain curves of (a) PVA-1, pure PVA-1/PVP, and PVP-1/PVP/plasticizer and (b) PVA-h, pure PVA-h/PVP, and PVA-h/PVP/plasticizer films as indicated. The insets in (a) and (b) are derived from pure PVA-1/PVP and pure PVA-h/PVP, respectively.

The mechanical properties of all the systems are shown in Table 4. The results showed that the plasticizers had a significant effect on the mechanical properties of the blends. The elongation at break increased with the addition of plasticizers because the plasticizers reduced the interactions between the polymer chains. This resulted in the reduction of the elastic modulus. This effect on plasticizing could be attributed to polymer-plasticizer interactions between the small molecules and the hydroxyl groups that hindered polymer-polymer interaction. ${ }^{34}$ Since the molar mass of glycerol is lower than that of sorbitol, the embedding of glycerol within the PVA and PVP matrix increased free volume leading to lower $T_{\mathrm{g}}$ and $T \mathrm{~m}$. 
Table 4. Tensile strength (TS), elongation at break (EB), Young's modulus (E), and toughness of PVA-1, PVA-1/PVP, PVA-h, and PVA-h/PVP films with and without plasticizers.

\begin{tabular}{lcccc}
\hline Sample & TS $(\mathrm{MPa})$ & EB $(\%)$ & E (MPa) & Toughness \\
& & & & $\left(10^{4} \mathrm{~J} \mathrm{~m}^{-3}\right)$ \\
\hline PVA-1 & $11.73 \pm 1.82$ & $105 \pm 13$ & $8.51 \pm 1.60$ & $949 \pm 162$ \\
PVA-1/PVP & $4.81 \pm 1.20$ & $74 \pm 21$ & $6.82 \pm 0.95$ & $411 \pm 120$ \\
PVA-1/PVP/GLY & $5.29 \pm 0.85$ & $782 \pm 34$ & $0.05 \pm 0.01$ & $2558 \pm 247$ \\
PVA-1/PVP/SOR & $8.45 \pm 1.25$ & $526 \pm 48$ & $0.52 \pm 0.12$ & $2844 \pm 581$ \\
PVA-1/PVP/GLY-SOR & $6.30 \pm 0.52$ & $733 \pm 53$ & $0.08 \pm 0.02$ & $2418 \pm 206$ \\
\hline PVA-h & $24.42 \pm 4.27$ & $231 \pm 41$ & $4.59+1.47$ & $4311 \pm 730$ \\
PVA-h/PVP & $4.26 \pm 1.28$ & $92 \pm 20$ & $6.24+0.94$ & $426+92$ \\
PVA-h/PVP/GLY & $4.18 \pm 0.62$ & $324 \pm 67$ & $0.17 \pm 0.04$ & $946 \pm 163$ \\
PVA-h/PVP/SOR & $11.39 \pm 1.14$ & $318 \pm 31$ & $1.47+0.20$ & $2511 \pm 475$ \\
PVA-h/PVP/GLY-SOR & $9.84+1.42$ & $393+39$ & $0.56+0.09$ & $2598 \pm 277$ \\
\hline
\end{tabular}

The introduction of glycerol, sorbitol, and their mixtures to the PVA-1/PVP blends improved the binary blend's tensile strength from 4.8 MPa to 5.3, 8.5, and 6.3 MPa, respectively. Simultaneously, the elongation at break increased considerably, which resulted in plasticized materials with a toughness of up to 7 times that of the binary blend. Similar trends were observed in the PVA-h/PVP blends, that yielded plasticized materials with toughness increased by factors of 2 (glycerol) and 6 (sorbitol and glycerol/sorbitol mixture). We note that in both types of blends sorbitol improved of tensile strength more effectively. 


\section{Conclusions}

We prepared super-tough polymer blends solely based on the biodegradable components PVA and PVP that were plasticized by natural molecules from glycerol and sorbitol. The introduction of sorbitol enhanced the crystallinity of the PVA/PVP blends and thereby improved their mechanical properties, without compromising their thermal stability. The structural, physical, and mechanical properties of the PVA/PVP blends were well correlated as a function of their plasticizers. This study highlighted an effective strategy towards the development of a new generation of polymeric blends that perform outstandingly, yet remain thoroughly biodegradable, and could effectively supplant existing materials in demanding applications.

\section{Acknowledgements}

The authors acknowledge and appreciate the research fund support (grant no. 158007) of the Faculty of Science, Prince of Songkla University. 


\section{References}

1. Nair, L. S.; Laurencin, C. T. Prog. Polym. Sci. 2007, 32, 762.

2. Gross, R. A.; Kalra, B. Science 2002, 297, 803.

3. Middleton, J. C.; Tipton, A. J. Biomaterials 2000, 21, 2335.

4. Sreekumar, P. A.; Al-Harthi, M. A.; De, S. K. J. Appl. Polym. Sci. 2012, 123, 135.

5. Shi, H.; Chen, X.; Chen, W.; Pang, S.; Pan, L.; Xu, N.; Li, T. J. Appl. Polym. Sci. 2017, DOI: 10.1002/APP.44732.

6. de Velde, K. V.; Kiekens, P. Polym. Test. 2002, 21, 433.

7. Vieira, M. G. A.; da Silva, M. A.; dos Santos, L. O. Eur. Polym. J. 2011, 47, 254.

8. Gaaz, T. S.; Sulong, A. B.; Akhtar, M. N.; Kadhum, A. A. H.; Mohamad, A. B.; AlAmiery, A. A. Molecules 2015, 20, 22833.

9. Baker, M. I.; Walsh, S. P.; Schwartz, Z., Boyan, B. D. J. Biomed. Mater. Res. B Appl. Biomater. 2012, 100, 1451.

10. Liu, M.; Guo, B.; Du, M.; Jia, D. Appl. Phys. A Mater. Sci. Process. 2007, 88, 391.

11. Chiellini, E.; Cinelli, P.; Corti, A., Kenawy, E. R. Polym. Degrad. Stab. 2001, 73, 549.

12. Park, S. J.; Park, J. W.; Ruckenstein, E. J. Appl. Polym. Sci. 2001, 80, 1825.

13. Rajeswari, N.; Selvasekarapandian, S.; Sanjeeviraja, C.; Kawamura, J.; Asath Bahadur, S. Polym. Bull. 2014, 71, 1061.

14. Chokshi, R. J.; Shah, N. H.; Sandhu, H. K.; Malick, A. W.; Zia, H. J. Pharm. Sci. 2008, 97, 2286.

15. Mondel, D.; Mollick, M. M. R.; Bhowmick, B.; Maity, D.; Bain, M. K.; Rana, D.; Mukhopadhyay, A.; Dana, K.; Chattopadhyay, D. Prog. Nat. Sci. Meter. Int. 2013, 23, 579. 
16. Ragab, H. M. Physica B 2011, 406, 3759.

17. Koczkur, K. M.; Mourdikoudis, S.; Polavarapu, L.; Skrabalak, S. E. Dalton Trans. 2015, 44, 17883.

18. de Gans, B. J.; Duineveld, P. C.; Schubert, U. S. Adv. Mater. 2004, 16, 203.

19. Liu, Y.; Varahramyan, K.; Cui, T. Macromol. Rapid Commun. 2005, 26, 1955.

20. Feng, H.; Feng, Z.; Shen, L. Polymer 1993, 34, 2516.

21. Nunes-Pereira, J.; Costa, C. M.; Lanceros-Méndez, S. J. Power Sources 2015, 281, 378.

22. Gökmeşe, F.; Uslu, İ.; Aytimur, A. Polym. Plast. Technol. Eng. 2013, 52, 1259.

23. Seabra, A. B.; de Oliveira, M. G. Biomaterials 2004, 25, 3773.

24. El-Houssiny, A. S.; Ward, A. A. M.; Mansour, S. H. ; Abd-El-Messieh, S. L. J. Appl. Polym. Sci. 2012, 124, 3879.

25. Aziz, S. B.; Rasheed, M. A.; Hussein, A. M.; Ahmed, H. M. Mater. Sci. Semicond. Process 2017, 71, 197.

26. Kumar, B.; Kaur, G.; Rai, S. B. Spectrochim. Acta A Mol. Biomol. Spectrosc. 2017, 187,75 .

27. Zidan, H. M.; El-Ghamaz, N. A.; Abdelghany, A. M.; Lotfy, A. Int. J. Electrochem. Sci. 2016, 11, 9041.

28. Selvasekarapandian, S.; Hirankumar, G.; Kawamura, J.; Kuwata, N.; Hattori, T. Matte. Lett. 2005, 59, 2741.

29. Baraker, B. M.; Lobo, B. J. Polym. Res. 2017, 24, 84.

30. Sejidov, F. T.; Mansoori, Y.; Goodarzi, N. J. Mol. Catal. A. Chem. 2005, 240, 186.

31. (a) Sothornvit, R.; Krochta, J. M. J. Agric. Food Chem. 2000, 48, 3913. (b)

Sothornvit, R.; Krochta, J. M. J. Agric. Food Chem. 2000, 48, 6298.

32. Pommet, M.; Redl, A.; Guilbert, S.; Morel, M. H. J. Cereal Sci. 2005, 42, 81. 
33. Snejdrova, E.; Dittrich, M. (2012). Pharmaceutically Used Plasticizers, Recent Advances in Plasticizers, Luqman, M. (Ed.), 2012, ISBN: 978-953-51-0363-9, InTech.

34. Mohsin, M.; Hossin, A.; Haik, Y. J. Appl. Polym. Sci. 2011, 122, 3102.

35. Mohsin. M.; Hossian, A.; Haik, Y. Mater. Sci. Eng. A 2011, 528, 925.

36. Selvam, S.; Sundrarajan, M. Carbohydr. Polym. 2012, 87, 1419.

37. Laot, C. M.; Marand, E.; Oyama, H. T. Polymer 1999, 40, 1095.

38. Liu, H.; Zhang, B.; Shi, H.; Tang, Y.; Jiao, K.; Fu, X. J. Mater. Chem. 2008, 18, 2573.

39. Hossain, U. H.; Seidl, T.; Ensinger, W. Polym. Chem., 2014, 5, 1001.

40. Chen, Y.; Cao, X.; Chang, P. R.; Huneault, M. A. Carbohydr. Polym., 2008, 73, 8.

41. Abdulwahid, R. T.; Abdullah, O. Gh.; Aziz, S. B.; Hussein, S. A.; Muhammad, F. F.; Yahya, M. Y. J. Mater. Sci. -Mater. Electron. 2016, 27, 12112.

42. Aziz, S. B. J. Electron. Mater. 2016, 45, 736.

43. Urpayil, S.; Thayyil, M. S. IOSR J. Pharm. 2012, 2, 17.

44. Patel, R. P.; Patel D. J.; Bhimani, D. B.; Patel, J. K. Dissolut. Technol. 2008, dx.doi.org/10.14227/DT150308P17.

45. Abdelrazek, E. M.; Elashmawi, I. S.; Labeeb, S. Physica B 2010, 405, 2021.

46. Thomas, P. S.; Guerbois, J. P.; Russell, G. F.; Briscoe, B. J. J. Therm. Anal. Cal. 2001, 64, 501 .

47. Dou, B.; Dupont, V.; Williams, P. T.; Chen, H.; Ding, Y. Bioresour. Technol. 2009, $100,2613$.

48. Birta, N.; Doca, N.; Valse, G.; Vlase, T. J. Therm. Anal. Cal. 2008, 92, 635.

49. Sanyang, M. L.; Sapuan S. M.; Jawaid, M.; Ishak, M. R.; Sahari, J. Polymers 2015, 7, 1106. 
50. Nishio, Y.; Haratani, T.; Takahashi, T.; Manley, R. St. J. Macromolecules 1989, 22 , 2547.

51. Brostow, W.; Chiu, R.; Kalogeras, I. M.; Vassilihou-Dova, A. Mater. Lett. 2008, 62, 3152.

52. Lewandoska, K. Eur. Polym. J. 2005, 41, 55.

53. Kalogeras, I. M.; Brostow, W. J. Polym. Sci. Part B Polym. Phys. 2009, 47, 80.

54. Nishio, Y.; Haratani, T.; Takahashi, T., J. Polym. Sci. Part B Polym. Phys. 1990, 28, 355.

55. Mano, V.; de Silva, M. E. S. R.; Barbani, N.; Giusti, P. J Appl. Polym. Sci. 2004, 92, 743. 